This synopsis is based on a report entitled 'Vogelhinder door middelgrote windturbines', Report 84/7, Research Institute for Nature Management, Arnhem, 1984. 113 pp., 16 figs., 12 tables, 52 refs., 16 appendices. Dutch, English summary.

Available as paper copy (order R032P, $f 17.50$ including postage) or on microfiche (order R032M, f 17.50 including postage) at: NARD, clo Pudoc, P.O. Box 4, 6700 AA Wageningen, Netherlands (telex 450515 blhwg $\mathrm{nl}$ ).

\title{
Behaviour and biological impact of (un)treated oil spills in estuarine areas
}

M. J. N. Bergman (Research Institute for Nature Management, Department of Estuarine Ecology, P.O. Box 59, 1790 AB Den Burg Texel, Netherlands)

Received 30 November 1984; accepted 6 March 1985

\begin{abstract}
The purpose of this study was to prepare recommendations for optimal nature management of the biologically rich Dutch estuarine coastal areas in case of an oil spill.

Key-words: estuaries, oil pollution, biological impact, clean-up methods.

Introduction. In recent years several large oil spills have occurred. Extensive literature on the impact and combat has since been published (Baker, 1976; McCarthy, Lindblom \& Walter, 1978). Especially in estuarine areas biological effects seemed severe, and the need was felt to compile a review of available literature in order to advice the managing authorities in case of oil spills threatening Dutch estuarine areas.
\end{abstract}

Methods. Hundreds of articles, dealing with fate and effects of (treated) oil were studied, using bibliographies, special reports about oil spills and articles on oil experiments in the field situation, in outdoor model ecosystems and in the laboratory. The compiled knowledge about behaviour and impact of oil in estuaries is translated into the specific situation of estuarine coastal areas in the Netherlands of which the Wadden Sea is the most important one.

\section{Conclusions}

Fate of oil. After its introduction in the Wadden Sea oil will occur as a floating film, varying in thickness from some $\mu \mathrm{m}$ to a few $\mathrm{cm}$ (in case of mousse formation). In the absence of mousse up to $40 \%$ of a light crude oil may evaporate within 48 hours. Oil 
products evaporate in the same period from a few $\%$ up to $70 \%$. During these first days up to $20 \%$ of the floating oil will also disperse as droplets of mainly 10 to $100 \mu \mathrm{m}$ in the sea water. Only a treatment with the latest (3rd generation) dispersants results in even smaller droplets of less than $10 \mu \mathrm{m}$. The percentage of oil which will dissolve in sea water is negligible.

Floating oil will rapidly be spread out over the total surface area of a tidal basin and will subsequently strand between the high and low water mark during ebb tide. Stranding will especially occur in areas with low current velocities: in the most inner parts and on the watersheds.

Dispersed oil will, by mixing and flushing, be transported in the whole tidal compartment of the Wadden Sea area where it is introduced. Due to less intensive exchange processes, chemical dispersion of floating oil in the most inner parts results in higher and more persistent concentrations of oil than chemical treatment near the outlets of the estuary. After a local maximum, the concentrations of dispersed oil decrease exponentially. Once dispersed, oil will adsorb to a large extent on suspended matter and hereafter accumulate and sedimentate in areas with the lowest current velocities. Besides, by adsorption, a lot of dispersed oil will be removed from the water column by zooplankton and zoobenthos. After ingestion, the oil will be incorporated and released in faecal pellets, which may sink to the bottom sediments.

Sedimentated or stranded oil will be redistributed repeatedly in exposed areas by wave action. In more sheltered muddy areas this process will be less as a result of the lower mechanical energy available, and here oil may be persistent for years.

Stranded oil will penetrate into the sediments. In percolating sandy sediments this penetration occurs up to the sinking water-level; in non-percolating sandy and muddy areas this process remains limited to the upper $6 \mathrm{~cm}$. Bioturbation increases this penetration significantly in all sediments to a depth of at least 20 to $30 \mathrm{~cm}$. As a result oil concentrations may be built up of some 100 to some $1000 \mathrm{mg} / \mathrm{kg}$.

Oil, either floating, dispersed, stranded or burried in the sediments, can be degradated by chemical and microbiological processes or by higher organisms. Oil will be broken down in aerobic sediments in about 1 year, in anaerobic sediments in some tens of years. In more sheltered areas in the Wadden Sea residual oil will persist for 3 to 6 years; in salt marshes periods of 10 years are not uncommon.

Biological impact. Floating oil may threaten birds and seals. Sedimented or stranded oil in thin layers from a few $\mu \mathrm{m}$ to $0.1 \mathrm{~mm}$ may affect and result in mortality among various groups of microorganisms, micro- and macrophytobenthos, lichens, seagrasses, zoobenthos, demersal fishes, breeding and resting birds, seals on resting places and vegetations on salt marshes. Oil penetrated into the sediment may cause mortality among some groups of infaunal organisms at concentrations higher than some hundreds of $\mathrm{mg} / \mathrm{kg}$; activities of some infaunal species are affected at oil concentrations from $10 \mathrm{mg} / \mathrm{kg}$.

Oil in the sea water, either dissolved, dispersed or adsorbed, can be harmful to microorganisms, phytoplankton, micro- and macrophytobenthos, zooplankton, zoobentos and fishes. Sublethal effects and mortality may occur at oil concentrations ranging from $10 \mu \mathrm{g} / \mathrm{kg}$ to some $10 \mathrm{mg} / \mathrm{kg}$ for the different species. 
Impact of clean-up methods. Although floating oil threatening the Wadden Sea can not be removed completely by mechanical methods during all whether conditions, still it is the recommended method. Fysico-chemical methods such as dispersion and sinking down will transfer the floating oil into the water column or on the bottom sediment, where the oil can still affect the organisms. The use of dispersants of the 2nd generation results in biological effects and mortality at concentrations of dispersant of some $10 \mathrm{mg} / \mathrm{kg}$ (concentrations of $1 \mathrm{mg} / \mathrm{kg}$ may cause effects on fish eggs). Treatment of oil with these dispersants results in effects and mortality at dispersed oil concentrations of some $10 \mathrm{mg} / \mathrm{kg}$ up to more than $1000 \mathrm{mg} / \mathrm{kg}$, depending on the kind of organism. Mechanical treatment of stranded oil does not reduce the direct effects on the benthic organisms. When this mechanical treatment results in a further penetration of oil into the sediments, the biological effects will even be more prolonged. Also dispersion of stranded oil will not reduce the direct effects on benthos and even more prolonged effects are likely in case of the expected deeper penetration of the chemically treated oil into the sediment.

Recommendations. According to Gundlach \& Hayes (1978) the Wadden Sea may be considered as an area moderately to extremely vulnerable to oil pollution. Oil spills in this estuary may always result in ecological effects, irrespective of the choosen clean-up method. Except the mechanical clean-up of floating oil, each treatment will cause improvements as well as damage to one or more groups of estuarine organisms. So the choice between these treatments will depend on conservation priorities. As a consequence of its central position in the marine food chain, the preservation of the benthic community on the tidal flats is thought to be of major importance. Therefore, the main priority in conservation of these estuarine areas in case of oil spills is given to this group of organisms. Moreover, treatments resulting in strong toxic effects of short duration are preferred to clean-up methods causing lower effects over a longer period.

Prevention of stranding of floating oil on the tidal flats has the highest priority. Otherwise oil will penetrate into the sediments, which will result in the persistence of oil and in biological effects for many years. After an oil spill the first step should be a mechanical clean-up of the floating oil, if possible combined with leading away the oil by booms to less vulnerable areas. When mechanical clean-up is insufficient to remove the major part, the floating oil should be dispersed chemically, preferably in the outlets to the sea, to prevent stranding of the floating oil. The fast exchange rates of the water masses in the Wadden Sea will cause a fairly rapid decrease of concentrations of dispersed oil. When mechanical and chemical treatment is not feasible, sinking and burning of the floating oil is undesirable. Floating oil stranding on the tidal flats, despite previous mechanical and chemical treatment, must be removed mechanically as quick as possible, either at high water when it floats again, or at low water on the dry flats. Mechanical methods, which result in the lowest penetration of oil in the sediments are preferred. Stranded oil should never be dispersed chemically because of the probably increased penetration of dispersed oil into the sediment. Burning of this oil is also not preferable. Oil in thin layers on salt marshes does not need any treatment, oil in layers of some $\mathrm{cm}$ should be 
treated mechanically.

Frightening away birds and seals of threatened places seems to be very unsuitable. In most cases the clean-up of oiled birds and seals is also little effective from the point of view of conservation of the population.

\title{
References
}

Baker, J. M., 1976. Marine ecology and oil pollution. Proceedings 'Marine ecology and oil pollution' (Aviemore, Scotland, 1975). John Wiley, New York, 556 pp.

Gundlach, E. R. \& M. O., Hayes, 1978. Vulnerability of coastal environments to oil spill impacts. Marine Technology Society Journal 12: 18-27.

McCarthy, L. T., G. P. Lindblom \& H. F. Walter, 1978. Chemical dispersants for the control of oil spills. Symposium American Society of Testing of Materials, Technical Publication 65, $507 \mathrm{pp}$.

This synopsis is based on a report entitled 'Gedrag, bestrijding en biologische effecten van olie in estuariene gebieden', Vol. 1. 'Literatuuroverzicht' (Literature review), 2 parts, 420 pp., 39 figs., 125 tables, 62 pp. of references; Vol. 2. 'Olie in de Waddenzee' (Oil in the Wadden Sea), 97 pp., 6 figs., 9 tables, 169 refs. RIN-Rapport 82/18 and 83/22, Research Institute for Nature Management (RIN), Arnhem/Leersum/ Texel, 1982/83. Dutch.

Available as paper copy (order R034P, $f 62.35$ (three parts) including postage) or on microfiche (order R034M, f37.50 including postage) at: NARD, clo Pudoc, P.O. Box 4, 6700 AA Wageningen, Netherlands (telex 45015 blhwg nl.)

Netherlands Journal of Agricultural Science 33 (1985) 81-84

\section{Acclimatization of anaerobic sludge for UASB reactor start-up}

\author{
W. J. de Zeeuw (AVEBE B.A., P.O. Box 15, 9640 AA Veendam, Netherlands) \\ Received 16 November 1984; accepted 17 January 1985
}

\begin{abstract}
The operation of UASB reactors during the initial start-up period was studied with unadapted seed material. Different types of sludge granules developed depending on the start-up conditions and the type of seed sludge used.

Keywords: anaerobic wastewater treatment, UASB reactor, start-up, granular sludge, biogas.
\end{abstract}

Introduction. The Upflow Anaerobic Sludge Bed (UASB) reactor represents a high-rate anaerobic wastewater treatment system (Lettinga et al., 1980). Most of the active biomass in the reactor is present in the form of sludge granules which possess excellent settling properties. If no acclimatized (granular) sludge is available, 